\title{
CORE-PERIPHERAL TEMPERATURE GRADIENT AND BLOOD LACTATE LEVEL AS MARKERS OF PROGNOSIS IN CHILDREN WITH DENGUE
}

\author{
Purvi Mittal', Shiv Ram Krishna Dubey22, Yashwant Kumar Rao 3 , Tanu Midha4, Gopal Nath Dwivedi ${ }^{5}$ \\ ${ }^{1}$ Senior Resident, Department of Paediatrics, GSVM Medical College, Kanpur. \\ ${ }^{2}$ Senior Resident, Department of Paediatrics, AIIMS, Bhopal. \\ ${ }^{3}$ Associate Professor, Department of Paediatrics, GSVM Medical College, Kanpur. \\ ${ }^{4}$ Associate Professor, Department of Community Medicine, GSVM Medical College, Kanpur. \\ 5 Professor, Department of Community Medicine, GSVM Medical College, Kanpur.
}

\section{ABSTRACT}

\section{BACKGROUND}

Severe Dengue is an important cause of childhood morbidity in many tropical regions. Dengue virus (DENV) infection leads to a range of outcomes including subclinical infection, undifferentiated febrile illness, Dengue fever (DF), life-threatening syndromes with fluid loss and hypotensive shock or other severe manifestations such as bleeding and organ failure. It therefore becomes essentially important to identify a child with physiological derangements in the early stages when signs are subtle, to monitor for warning signs and other clinical parameters in order to recognise progression to the critical phase and therefore predictability of mortality in the early stages when the symptoms are not very marked.

The aim of the study was to assess the utility of non-invasive, inexpensive clinical methods, arterial lactate level and coreperipheral temperature gradient as prognostic indicators in children with dengue.

\section{MATERIALS AND METHODS}

This was a prospective observational study conducted in the paediatric emergency ward/ ICU of Department of Paediatrics, GSVM Medical College, Kanpur. Subjects were all suspected cases of dengue aged between 1 year and 18 years, attending the paediatric emergency ward/ ICU of Dept. of Paediatrics between 1st July 2014 and 31st June 2015. Arterial lactate level and core-peripheral temperature gradient of confirmed cases were recorded at the time of admission. ROC analysis and multiple logistic regression analysis were used to analyse the data.

\section{RESULTS}

Out of 115 confirmed dengue cases, 16 patients were lost for followup. Of the remaining 99 cases, there were 67 males and 32 females in the range of age group of 1 year to 18 years. Mean age of males was $6.02 \pm 3.28$ years and mean age of females was 10.28 \pm 3.85 years. ROC curve analysis showed that core to peripheral temperature gradient and arterial lactate levels had similar predictive values for increased risk of mortality (area under the curve, 0.807 and 0.877 , respectively) with the best cut-off values of $2.9^{\circ} \mathrm{C}$ for core to peripheral temperature gradient and $36 \mathrm{mg} / \mathrm{dL}$ for blood lactate levels.

\section{CONCLUSION}

Raised arterial lactate levels above $36 \mathrm{mg} / \mathrm{dL}$ and core to peripheral temperature gradient $\geq 2.9^{\circ} \mathrm{C}$ have a good prognostic value as a marker of mortality children with dengue.

\section{KEYWORDS}

Core to Peripheral Temperature, Dengue, Lactate Level.

HOW TO CITE THIS ARTICLE: Mittal P, Dubey SRK, Rao YK, et al. Core-peripheral temperature gradient and blood lactate level as markers of prognosis in children with dengue. J. Evolution Med. Dent. Sci. 2017;6(68):4863-4867, D0I: 10.14260/Jemds/2017/1054

\section{BACKGROUND \\ Severe Dengue is an important cause of childhood morbidity in many tropical regions. There is a consensus from studies in Southeast Asian and Latin American countries that children are particularly at risk of developing severe disease and carry a higher mortality rate. ${ }^{[1,2]}$ National vector borne disease control program reported 64058 dengue cases all over India in the year 2015, no. of deaths being 135.[3] It therefore}

Financial or Other, Competing Interest: None.

Submission 20-07-2017, Peer Review 11-08-2017,

Acceptance 19-08-2017, Published 24-08-2017.

Corresponding Author:

Dr. Purvi Mittal,

Flat No. 701, Dilkash Haribansh Apartments,

River Bank Colony, Lucknow.

E-mail: purvimittal@gmail.com

DOI: $10.14260 /$ jemds/2017/1054 becomes essentially important to identify a child with physiological derangements in the early stages when signs are subtle. It is a disease that is complex in its manifestations, hence correct and timely intervention if instituted is effective in saving lives as the management is relatively simple and inexpensive. It can be difficult to distinguish dengue clinically from non-dengue febrile diseases in the early febrile phase.

A positive tourniquet test in this phase indicates an increased probability of dengue.[4,5] However, these clinical features do not predict the severity of disease. The period of clinically significant plasma leakage usually lasts $24-48$ hours. Shock occurs when a critical volume of plasma is lost through leakage. It is often preceded by warning signs. The body temperature may be subnormal when shock occurs. Therefore, it is crucial to monitor for warning signs and other clinical parameters in order to recognise progression to the critical phase and therefore predictability of mortality in the 
early stages when the symptoms are not very marked. Lactate has been found elevated in shock states of varied aetiologies and correlates with high mortality.[6] Circulatory shock is the commonest cause of hyperlactataemia and the presence of increased blood lactate in shock signifies a poor prognosis. Core to peripheral temperature gradient is a simple bedside test done for initial evaluation of the patients.[7] It is advocated as non-invasive method for assessment of hypoperfusion in critically ill children. ${ }^{[8]}$

With this background, we conducted our study to determine the role of blood lactate level and core-peripheral temperature as early predictors of outcome and mortality in children with dengue.

\section{MATERIALS AND METHODS}

\section{Study Design}

This was a prospective observational study conducted in the paediatric emergency ward/ ICU of Dept. of Paediatrics, GSVM Medical College, Kanpur. Subjects were all suspected cases of dengue aged between 1 year and 18 years, attending the paediatric emergency ward/ ICU of Dept. of Paediatrics between 1st July 2014 and 31st June 2015. Blood samples were collected and were sent for dengue testing. When febrile children presented during the first four days of the illness, blood was tested for the NS1 antigen and blood tests were repeated on Day 7 to 10 of the illness for dengue IgM and IgG antibodies. An infrared thermometer (Fluke $62 \mathrm{Mini}$ Infrared Thermometer) was used to measure both tympanic (core temperature) and great toe (peripheral temperature), the latter by holding the instrument just above the skin.[9] These measurements were made only once and the temperature gradient and the arterial lactate level of these children were determined at the time of admission. To determine the blood lactate level at admission, an arterial sample was collected in the first 2 hours after a child's admission to the PICU. The sample was collected directly into a tube containing anticoagulant. The blood concentration of lactate was measured immediately using an automatic biomedical blood gas analyser (CCX, NOVA Biomedical, Waltham, MA, USA) as part of a routine panel of blood gas tests in our clinical laboratory with the electrode method, and it was expressed in millimole per litre ( $\mathrm{mmol} / \mathrm{L})$. The coefficient of variation was $7.5 \%$ at the low level and $5.0 \%$ at the high level. The normal range in children is $5-15 \mathrm{mg} / \mathrm{dL}$. The laboratory investigators were blinded to the sample sources and clinical outcomes. All the children admitted with suspected dengue had other routine tests such as full blood counts, blood urea nitrogen and electrolytes, and random blood sugar. Other tests were requested based on the clinical presentations. Blood, urine cultures were done in all sick children and in children with uncertain diagnosis. A team of paediatricians managed the children, and other specialty consultations were sought where necessary. None of these children were subjected to any investigations or interventions that were not a routine practice at this hospital. ROC analysis and multiple logistic regression analysis were used to analyse the data.

\section{Definitions}

The World Health Organisation (WHO) and Pan American Health Organisation (PAHO) definitions and criteria were used to classify dengue disease.[10,11] Clinically, dengue infection was categorised into dengue, dengue with warning signs and severe dengue.[10] Dengue is defined by the presence of fever with two or more of the following features: rash, nausea and vomiting, aches and pains, a positive tourniquet test, leucopaenia and any one of the warning signs. Warning signs include persistent vomiting, abdominal pain or tenderness, clinical fluid accumulation, mucosal bleed, lethargy or restlessness, and rapidly rising haematocrit or falling platelets. Dengue cases were considered confirmed if DEN NS1 antigen was detected or there was a positive IgM antibody titre.

\section{RESULTS}

Over a period of one year, 167 cases of suspected dengue were admitted in the hospital. Out of these 167 cases 115 were confirmed dengue cases, 16 patients were lost for followup. Of the remaining 99 cases, there were 67 males and 32 females in the range of age group of 1 year to 18 years. Mean age of males was $6.02 \pm 3.28$ years and mean age of females was $10.28 \pm 3.85$ years.

ROC curve analysis showed that core to peripheral temperature gradient and blood lactate levels had similar predictive values for increased risk of mortality (area under the curve, 0.807 and 0.877 respectively) with the best cut-off values of $2.9^{\circ} \mathrm{C}$ for core to peripheral temperature gradient and $36 \mathrm{mg} / \mathrm{dL}$ for blood lactate levels.

For core to peripheral temperature gradient area under the curve was 0.807 ( 0.715 to 0.879$)$ and this was statistically significant $(\mathrm{p}<0.0001)$. At cut-off level $2.9^{\circ} \mathrm{C}$, sensitivity was $79 \%$ and specificity was $89 \%$. The graph for a range of values of core to peripheral temperature gradient are shown in the ROC curve in Fig. 1.

The graph for a range of values of blood lactate level are shown in the ROC curve in Fig. 2. Area under the curve was 0.877 (0.795 to 0.934 ) and this was statistically significant ( $p$ $<0.0001$ ). At cut-off level $36 \mathrm{mg} / \mathrm{dL}$, sensitivity was $89 \%$ and specificity was $76 \%$. All the non-survivors were found to have blood lactate level $>36 \mathrm{mg} / \mathrm{dL}$.

Table 1 shows that overall mortality was 9 (9.1\%), out of total 99 cases. All the cases who died had blood lactate levels $\geq 36 \mathrm{mg} / \mathrm{dL}$, which was found to be significant $(\mathrm{p}<0.001)$. Thirty-six (40\%) cases who survived had blood lactate level of more than $36 \mathrm{mg} / \mathrm{dL}$ and $54(60 \%)$ cases among the survivors had level below $36 \mathrm{mg} / \mathrm{dL}$. The mean age of patients who survived was $5.17 \pm 2.6$ years, mean age of nonsurvivors was $5.83 \pm 3.5$. This difference in age was not found to be significant. Among all the cases who died, 8 (88.9\%) had core to peripheral temperature gradient $\geq 2.9^{\circ} \mathrm{C}$, which was significantly higher ( $\mathrm{p}<0.0001$ ) than those with core to peripheral temperature gradient $<2.9^{\circ} \mathrm{C}$. No significant difference was found in the survival rate of males and females.

Upon multiple logistic regression analysis, lactate level $(\mathrm{OR}=1.057)$ was found to be significantly associated with survival $(p=0.019)$. Association of core to peripheral temperature gradient $(\mathrm{OR}=1.301)$ and mortality was not significant $(p=0.476)$ [Table 2]. 
Core-Peripheral Temperature Gradient

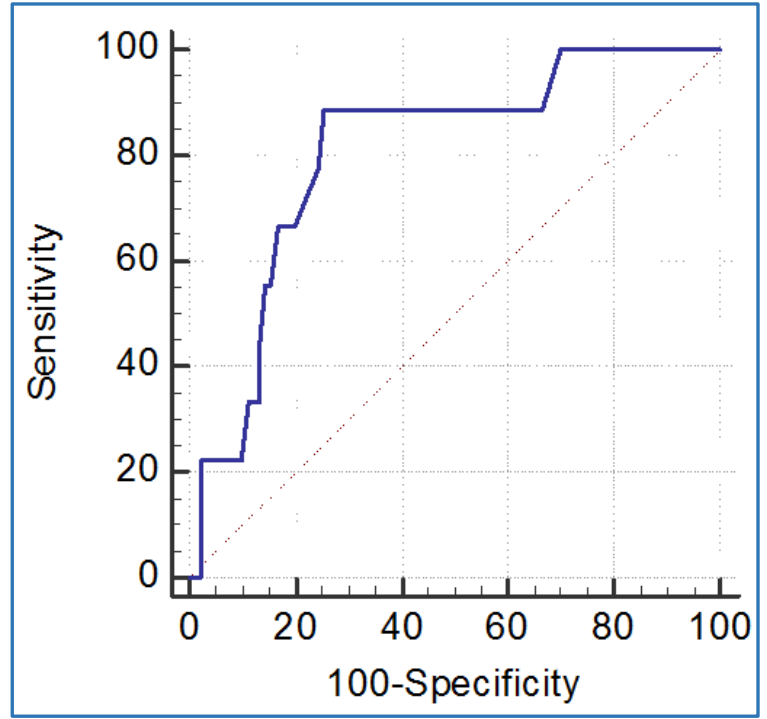

Figure 1. ROC Analysis of Core to Peripheral Temperature Gradient as Predictor of Mortality in Critically Ill Children. Area under the Curve $=0.807$ (0.715 to 0.879)
Blood Lactate Level

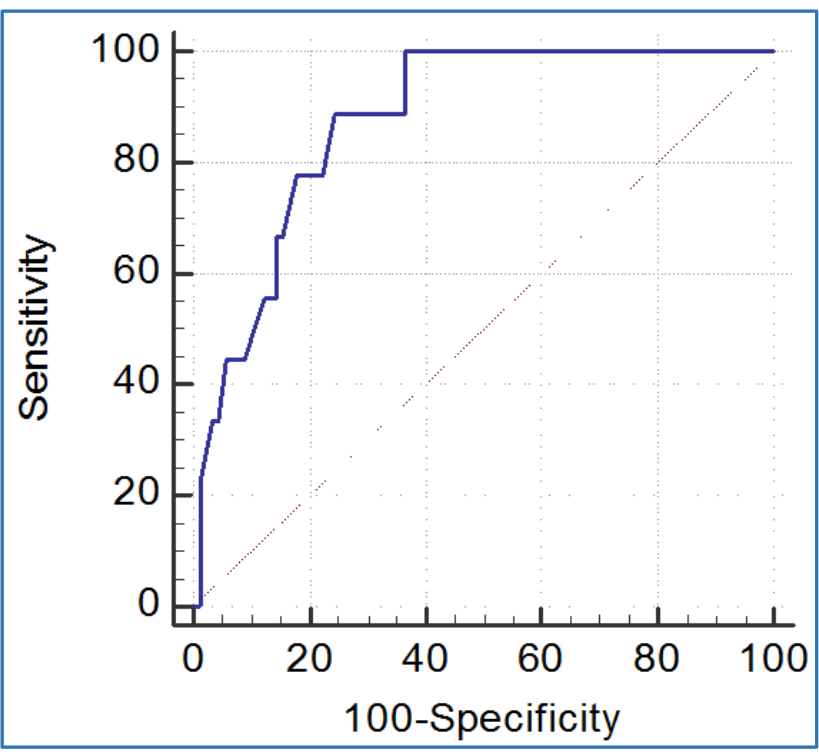

Figure 2. ROC Analysis of Blood Lactate Level as

Predictor of Mortality Children with Dengue.

Area under the Curve $=0.877$ (0.795 to 0.934)

\begin{tabular}{|c|c|c|c|}
\hline Determinant & Non- Survivor (9) & Survivor (90) & P-Value \\
\hline Age & $5.83 \pm 3.5$ & $5.17 \pm 2.6$ & $P=0.602$ \\
\hline \multicolumn{4}{|c|}{ Sex } \\
\hline Male & $6(8.9 \%)$ & $61(90.9 \%)$ & \multirow{2}{*}{$P=0.946$} \\
\hline Female & $3(9.3 \%)$ & $29(88.7 \%)$ & \\
\hline \multicolumn{4}{|c|}{ Core to Peripheral Temperature Gradient } \\
\hline$\geq 2.9^{\circ} \mathrm{C}$ & $8(88.9 \%)$ & $26(28.9 \%)$ & \multirow{2}{*}{$P=0.001$} \\
\hline$<2.9$ & $1(11.1 \%)$ & $64(71.1 \%)$ & \\
\hline \multicolumn{4}{|c|}{ Blood Lactate Level } \\
\hline$>36 \mathrm{mg} / \mathrm{dL}$ & $9(100 \%)$ & $36(40 \%)$ & \multirow[t]{2}{*}{$\mathrm{p}<0.001$} \\
\hline$<36 \mathrm{mg} / \mathrm{dL}$ & $0(0 \%)$ & $54(60 \%)$ & \\
\hline
\end{tabular}

\begin{tabular}{|c|c|c|c|c|c|c|}
\hline Determi-nant & $\begin{array}{c}\text { B } \\
\text { Coefficient }\end{array}$ & SE & OR & $\begin{array}{c}\text { 95\% CI } \\
\text { Lower Limit }\end{array}$ & $\begin{array}{c}\text { 95\% CI } \\
\text { Upper Limit }\end{array}$ & $\begin{array}{c}\text { P- } \\
\text { Value }\end{array}$ \\
\hline Age &.- .033 & .123 & .968 & .761 & 1.230 & 0.789 \\
\hline Sex & .383 & .898 & 1.467 & .252 & 8.535 & 0.670 \\
\hline Core to peripheral gradient & .263 & .370 & 1.301 & .631 & 2.685 & 0.476 \\
\hline $\begin{array}{c}\text { Blood lactate } \\
\text { level }\end{array}$ & .056 & .024 & 1.057 & 1.009 & 1.108 & 0.019 \\
\hline
\end{tabular}

\section{DISCUSSION}

To the best of our knowledge, this is the first study to assess the core to peripheral temperature gradient and serum lactate levels as a marker of mortality in children suffering from dengue. Peripheral circulation is influenced by cardiac output and the tone of the arteriolar vessels, which are in turn affected by numerous interrelated factors such as blood volume, myocardial contractility, sympathetic nervous system stimulation, circulating vasoactive substances and local homeostatic mechanisms. Measuring the skin temperature provides an indirect and non-invasive assessment of the state of the peripheral circulation. Much of the published evidence on the temperature has focussed on its clinical applications in shock. Studies have indicated that changes in peripheral temperature have prognostic and diagnostic value in hypovolaemic and cardiogenic shock and can be used as a non-invasive guide to adequacy of haemodynamic status.[12,13,14] Kholoussy AM had reported that monitoring the central peripheral temperature gradient in critically ill surgical patients is a simple, sensitive, noninvasive and inexpensive method that can accurately reflect the state of peripheral circulation.[13] In our study, the ROC curve analysis showed the best cut-off value of $2.9^{\circ} \mathrm{C}$. Among the non-survivors, $8(88.9 \%)$ had core to peripheral temperature gradient $\geq 2.9^{\circ} \mathrm{C}$, which was significantly higher $(\mathrm{p}<0.0001)$ than those with core to peripheral temperature gradient $<2.9^{\circ} \mathrm{C}$. This is in concordance with the findings reported by Rao YK et al in a similar study on predictability of core to peripheral temperature gradient in the outcome of critically ill children. They found that mortality was higher in 
cases with core to peripheral temperature gradient $\geq 3.4^{\circ} \mathrm{C}$, as compared to those with core to peripheral temperature gradient $<3.4^{\circ} \mathrm{C} .{ }^{[8]}$

Many studies have reported the utility of raised lactate level as a prognostic marker in predicting the outcome in critically ill patients.[15,16,17] In our study the ROC curve assessment revealed cut-off level of $36 \mathrm{mg} / \mathrm{dL}$ with sensitivity of $89 \%$ and specificity of $76 \%$, all the nonsurvivors had blood lactate level $>36 \mathrm{mg} / \mathrm{dL}$. Among the survivors $40 \%$ had blood lactate level $>36 \mathrm{mg} / \mathrm{dL}$ and $60 \%$ cases had blood lactate level $<36 \mathrm{mg} / \mathrm{dL}$. Similar findings were reported by Koliski A et al, who observed 31\% mortality among patients with blood lactate level $>18 \mathrm{mg} / \mathrm{dL}$ as compared to $13 \%$ among patients with level $<18 \mathrm{mg} / \mathrm{dL} .{ }^{[15]}$ Jansen et al observed $20 \%$ mortality among patients with hyperlactataemia on admission.[17] Bai et al evaluated the predictive value of blood lactate levels at admission and determined the cut-off values for predicting in-hospital mortality in the critically ill paediatric population. Median (interquartile range) blood lactate level in critically ill children was $3.2 \mathrm{mmol} / \mathrm{L}(2.2-4.8)$. The blood lactate level upon admission was significantly associated with mortality (odds ratio $[\mathrm{OR}]=1.38$ ).[18]

Scott HF et al sought to test the utility of lactate testing in paediatric emergency department (ED) patients with systemic inflammatory response syndrome (SIRS). The hyperlactataemia group had a relative risk of $5.5(95 \%$ confidence interval $[\mathrm{CI}]=1.9$ to 16.0 ) of developing 24-hour organ dysfunction. Among undifferentiated children with SIRS, early hyperlactataemia is significantly associated with increased risk of organ dysfunction, resuscitative therapies and critical illness.[19]

Upon multiple logistic regression analysis, lactate level $(\mathrm{OR}=1.057)$ was found to be significantly associated with mortality $(p=0.019)$; however, the association of core to peripheral temperature gradient with mortality was not found to be significant $(\mathrm{p}=0.476)$.

\section{CONCLUSION}

Raised blood lactate levels above $36 \mathrm{mg} / \mathrm{dL}$ and core to peripheral temperature gradient $\geq 2.9^{\circ} \mathrm{C}$ have a good prognostic value as a marker of mortality children with dengue. Core to peripheral temperature gradient measurement is a simple and non-invasive technique to assess the state of peripheral circulation and has been reported by the previous studies too as a good indicator of haemodynamic status and prognostic marker of outcome. It should be routinely used to assess the clinical status of children with dengue who may present early with very subtle clinical signs and symptoms. Further studies should be extended on its role in the assessment of children suffering from various other serious ailments.

\section{REFERENCES}

[1] Anderson KB, Chunsuttiwat S, Nisalak A, et al. Burden of symptomatic dengue infection in children at primary school in Thailand: a prospective study. Lancet 2007;369(9571):1452-9.

[2] Guzman MG, Kouri G, Bravo J, et al. Effect of age on outcome of secondary dengue 2 infections. Int J Infect Dis 2002;6(2):118-24.
[3] Dengue cases and deaths in the country since 2009. Available from:

http://www.nvbdcp.gov.in/den-cd.html.

[4] Kalayanarooj S, Vaughn DW, Nimmannitya S, et al. Early clinical and laboratory indicators of acute dengue illness. Journal of Infect Dis 1997;176(2):31321.

[5] Cao XT, Ngo TN, Wills B, et al. Evaluation of the World Health Organization standard tourniquet test and a modified tourniquet test in the diagnosis of dengue infection in Vietnam. Tropical Medicine and International Health 2002;7(2):125-32.

[6] Shapiro NI, Howell MD, Talmor D, et al. Serum lactate as a predictor of mortality in emergency department patients with infection. Ann Emerg Med 2005;45(5):524-8.

[7] Pamba A, Maitland K. Capillary refill: prognostic value in Kenyan children. Arch Dis Child 2004;89(10):950-5.

[8] Rao YK, Midha T, Taneja G, et al. A study on the prognostic value of core to peripheral temperature gradient and blood lactate levels in critically ill children in a tertiary care hospital in Kanpur, India. J Pediatr Infect Dis 2013;8(4):155-9.

[9] Vincent JL, De MA, Cantraine F, et al. Use of the SOFA score to assess the incidence of organ dysfunction/failure in intensive care units: results of a multicenter, prospective study. Working group on sepsis-related problems of the European society of intensive care medicine. Crit Care Med 1998;26(11):1793-800.

[10] World Health Organization. Dengue: guidelines for diagnosis, treatment, prevention and control, $3^{\text {rd }}$ edn. Geneva: WHO 2009. Available:

http://www.who.int/csr/resources/publications/den gue_9789241547871/en.

[11] Pan American Health Organization. Dengue and dengue hemorrhagic fever in the Americas: guidelines for prevention and control. Washington, DC: PAHO 1994.

[12] Matthews HR, Meade JB, Evans CC. Significance of prolonged peripheral vasoconstriction after openheart surgery. Thorax 1974;29(3):343-8.

[13] Kirklin JK, Blackstone EH, Kirklin JW, et al. Intracardiac surgery in infants under age 3 months: predictors of postoperative in-hospital cardiac deaths. Am J Cardiol 1981;48(3):507-12.

[14] Lambert HJ, Baylis PH, Coulthard MG. Centralperipheral temperature difference, blood pressure, and arginine vasopressin in preterm neonates undergoing volume expansion. Arch Dis Child Fetal Neonatal Ed 1998;78(1):F43-5.

[15] Koliski A, Cat I, Giraldi DJ, et al. Blood lactate concentration as prognostic marker in critically ill children. J Pediatr Rio J 2005;81(4):456-60.

[16] Jansen TC, Bommel J, Mulder PG, et al. The prognostic value of blood lactate levels relative to that of vital signs in the pre-hospital setting. Crit Care 2008;12(6):R160. 
[17] Jansen TC, van Bommel J, Woodward R, et al. Association between blood lactate levels, sequential organ failure assessment subscores, and 28-day mortality during early and late intensive care unit stay: a retrospective observational study. Crit Care Med 2009;37(8):2369-74.

[18] Scott HF, Donoghue AJ, Gaieski DF, et al. The utility of early lactate testing in undifferentiated pediatric systemic inflammatory response syndrome. Academic emergency medicine 2012;19(11):1276-80.
[19] Bai Z, Zhu X, Li M, et al. Effectiveness of predicting inhospital mortality in critically ill children by assessing blood lactate levels at admission. BMC Pediatrics 2014;14:83. 